\section{Female reproductive factors and primary open-angle glaucoma in the Nurses' Health Study}

LR Pasquale ${ }^{1,2}$ and $\mathrm{JH}$ Kang $^{2}$

\section{Abstract}

Purpose The purpose of this study was to explore the relation between age at menarche, parity, and oral contraceptive (OC) use, and primary open-angle glaucoma (POAG). Methods We followed 79440 women in the Nurses' Health Study prospectively from 1980 to 2006 and identified 813 cases of incident POAG. Eligible participants were $\geq 40$ years old, free of POAG at baseline, had information on reproductive history, and reported receiving eye examinations during follow-up. Relevant exposure data and POAG risk factors were updated using biennial questionnaires. We used proportional hazards models to calculate multivariable rate ratios (MVRRs) of POAG and $95 \%$ confidence intervals (CI). Results In multivariable analysis, there were no significant linear trends between age at menarche ( $P$ for trend $=0.65$ ) or reproductive duration defined as time between age at menarche and menopause $(P$ for trend $=0.30$ ) and POAG. Although ever using OCs was not associated with POAG risk (MVRR $=1.14$; $95 \% \mathrm{CI}, 0.98,1.34), \geq 5$ years of OC use was associated with a modest $25 \%$ increased risk of POAG (MVRR $=1.25 ; 95 \% \mathrm{CI}, 1.02,1.53 ; P$ for linear trend $=0.04)$. Furthermore, among past OC users, a shorter time since stopping OC use was also associated with an increased risk of POAG ( $P$ for linear trend $=0.02$ ). Parity was not associated with POAG risk.

Conclusion The $\geq 5$ years of OC use was associated with a modestly increased risk of POAG. These data add further support for a role of circulating estrogen in the pathogenesis of POAG.

Eye (2011) 25, 633-641; doi:10.1038/eye.2011.34;

published online 18 February 2011

Keywords: female reproductive factors; age at menarche; parity; oral contraceptives; primary open angle glaucoma

\section{Introduction}

There is emerging evidence that estrogen metabolism has an important role in the pathogenesis of primary open-angle glaucoma (POAG). Among women $\geq 65$ years, early age of menopause $(\leq 45 \text { years })^{1}$ was associated with an increased risk of POAG, whereas later age of onset of menopause $(\geq 54 \text { years })^{2}$ was associated with a decreased risk of POAG. Several studies indicate that postmenopausal hormone (PMH) use is associated with modest reductions in intraocular pressure (IOP). ${ }^{3-8}$ Current use of combined estrogen and progestin replacement therapy was associated with a reduced risk of high-tension $\mathrm{POAG}^{2}$ (where the IOP was $\geq 22 \mathrm{~mm} \mathrm{Hg}$ at diagnosis) and interacted with common endothelial nitric oxide synthase polymorphisms in modifying the risk of high-tension POAG. ${ }^{9}$

Given the associations between factors related to menopause and POAG, it is also important to assess any links between reproductive factors before menopause and this neurodegenerative disease. Retinal ganglion cells express estrogen receptors, ${ }^{10}$ and estrogen has beneficial effects in animal models of neurodegenerative disorders, ${ }^{11,12}$ including glaucoma. ${ }^{13,14}$ During pregnancy, when circulating estrogen levels are high, healthy women experience decreased $\mathrm{IOP}^{15-18}$ despite a concomitant increase in central corneal thickness. ${ }^{19}$ Cumulative endogenous and exogenous estrogen exposures during the reproductive years can vary depending on the age at menarche, duration of the reproductive period (time from menarche to menopause), parity and oral contraceptive (OC) use.

We assessed age at menarche, reproductive duration, parity and OC use in relation to incident POAG among 79440 women in the Nurses' Health Study (NHS) who were followed for $25+$ years. To the best of our
${ }^{1}$ Department of Ophthalmology, Massachusetts Eye and Ear Infirmary, Brigham and Women's Hospital, Harvard Medical School, Boston, MA, USA

${ }^{2}$ Channing Laboratory, Department of Medicine, Brigham and Women's Hospital, Harvard Medical School, Boston, MA, USA

Correspondence: LR Pasquale, Department of Ophthalmology, Massachusetts Eye and Ear Infirmary, Brigham and Women's Hospital, Harvard Medical School, 243 Charles Street, Boston, MA 02114, USA.

Tel: + 1617573 3674;

Fax: + 16175734300 .

E-mail: Louis_Pasquale@ meei.harvard.edu

Received: 5 January 2011 Accepted in revised form: 31 January 2011 Published online: 18 February 2011

This work is scheduled for presentation at the annual American Glaucoma Society Meeting in Dana Point, CA, USA on 4 March 2011. 
knowledge, this is the first prospective cohort study of reproductive factors and the risk of POAG.

\section{Materials and methods}

\section{Population for current study}

NHS was launched in 1976 when 121700 United States female registered nurses aged 30-55 years completed a baseline questionnaire about lifestyle habits, reproductive attributes, and medical history. Follow-up biennial questionnaires were used to update this data and report newly diagnosed medical conditions including glaucoma.

For this study, the follow-up was from 1980 to 2006. Eligible participants contributed to the study if they reached age 40 years (as glaucoma risk increases after age 40 years) and if they reported having had an eye exam in the period at risk (to minimize possible detection bias). Eligible participants contributed person-time in 2-year units from the return date of the first biennial questionnaire until the occurrence of a report of glaucoma, cancer (because cancer diagnoses can greatly impact lifestyle choices), death, or loss to follow-up, or until 2006, whichever came first. For each 2-year period at risk, participants' person-time was categorized based on the responses from the most recent questionnaire.

Of the 121700 women in the NHS, participants were excluded for the following reasons as of 1980: (1) 29233 failed to respond or provide adequate information on a 1980 semiquantitative food frequency questionnaire (FFQ; selected dietary exposures such as alcohol consumption and caffeine intake that might alter IOP and POAG risk were included as covariates in our models ${ }^{20,21}$ and the first dietary assessments occurred in 1980), (2) 3624 with prevalent cancers excluding non-melanoma skin cancer, (3) 833 with a prevalent diagnosis of glaucoma or glaucoma suspect, (4) 737 lost to follow-up immediately after baseline, (5) 5972 who never reported an eye examination during follow-up; these exclusions left 81301 women. For the first 2-year cycle at risk (1980-1982), 44904 women were eligible to contribute person-time after we excluded 36397 temporarily ineligible women (17208 who were $<40$ years old and 19189 who did not report receiving an eye exam when first asked; see below); at later periods, if these 36397 temporarily ineligible women reached 40 years of age and reported receiving eye exams, they became eligible to contribute person-time. Hence, by 2006, a total of 79440 women contributed person-time. Follow-up rates were high ( $>95 \%$ of the total possible person-time).

At each 2-year follow-up cycle, only women who indicated they received an eye exam in the previous 2 years were eligible to contribute person-time to the study. For example, if a participant specified she had an eye exam only in 2000 and 2002, then she contributed person-time only during 1998-2000 and 2000-2002. Because we first inquired about eye exams in 1990, eye exam eligibility was determined this way from 1988 onwards. For the initial periods of 1980-1988, eye exam eligibility was based on responses to the 1990 question.

\section{Assessment of reproductive factors}

Age at menarche and age at menopause Starting in 1976, we recorded the ages when menstrual periods began and when they ceased permanently. Additional questions were asked of menopausal women, including type of menopause (natural, surgical, or radiation) and, if surgical menopause, the number of ovaries removed. Menopausal status was updated biennially.

Parity Parity, defined as pregnancy lasting at least 6 months, was assessed in 1976 and biennially updated through 1984 and then again in 1996.

OC use Current and past OC use was asked in 1976 and updated biennially until 1984, at which point no women reported current use. After 1984, OC use was defined as ever/never. Further, women were asked to report the time periods for which they used OCs and the reasons for stopping.

PMH use A question on PMH use was asked biennially beginning in 1976. Specifically, in 1976, women were asked if following the cessation of menstruation, they took female hormones and if so, for how long. Beginning in 1984, women were asked about specific types of PMH use allowing classification of estrogen only, progestin only or combination hormone use.

The information on reproductive and menopausal factors provided by our participants has been found to be highly accurate. A validation study in a related cohort (NHS II) comparing questionnaire reports of OC use to use reported during a telephone interview reported a 99\% agreement for ever use of OCs and a high correlation for duration of use $(r=0.94){ }^{22}$ Furthermore, among women reporting surgical menopause on the 1976 questionnaire, 95\% accurately reported their age at menopause to within 1 year on the 1980 questionnaire. ${ }^{23}$ Also, we obtained medical records from a random sample of women reporting surgical menopause in the 1982 questionnaire; medical record review indicated that in $99 \%$ of cases, there was complete agreement between the self-report and the details of the type of surgery performed. Finally, we have measured circulating estradiol levels in women who reported natural or 
surgical menopause and found levels that were consistent with the menopausal status derived from questionnaire data. ${ }^{24-26}$

\section{Case ascertainment}

We used the same case definition and methodology to identify participants with POAG used in a study of female reproductive aging and POAG. ${ }^{2}$ Briefly, we asked participants if they received a diagnosis of glaucoma beginning in 1990. We subsequently retrieved medical information from diagnosing clinicians and reviewed them for evidence of open-angles, absence of secondary causes of elevated IOP and reproducible visual field loss consistent with nerve fiber layer insult on at least two reliable tests. Our previous studies have revealed associations with established POAG risk factors such as age, African heritage, and family history, demonstrating construct validity of our case definition. ${ }^{20}$ To confirm participants self-reporting POAG, all the medical information of the self-reported cases underwent two independent reviews by a glaucoma specialist (LRP) masked to information on participants' reproductive status and OC use.

During follow-up, 6609 women reported a glaucoma diagnosis. These were confirmed by eye doctors in $67 \%$ as follows: POAG with VF loss $(26 \%)$, only elevated IOP or optic disk cupping (22\%) and other types of glaucoma or glaucoma suspects (19\%). The remaining 33\% of self-reports could not be confirmed as the participants themselves $(5 \%)$ or their eye doctors $(4 \%)$ could not be contacted, participants did not give permission to review their records $(11 \%)$, participants indicated that the initial report was in error $(11 \%)$ or participants' eye doctors disconfirmed the diagnosis of POAG (2\%). Of the 1679 women confirmed to have POAG with VF loss by their doctors, 813 met the case definition criteria. Participants who self-reported glaucoma but were either disconfirmed or could not be confirmed as POAG cases were censored from contributing person-time as of the time of their self-reported date of glaucoma diagnosis.

\section{Statistical analysis}

The study population differed for each attribute of reproductive health depending on the availability of the exposures of interest. For example, for the reproductive duration, defined as the time between age at menarche to age at menopause, the analysis was restricted to women with natural menopause. We calculated incidence rates of POAG by dividing the incident cases by person-years according to exposure groups. For all analyses, we first calculated Mantel-Haenszel age-adjusted rate ratios and their $95 \%$ confidence intervals (CIs). We then calculated multivariable relative risks (MVRRs) and 95\% CIs by simultaneously controlling for potential glaucoma risk factors (see below) in Cox proportional hazards analyses stratified by age in months and the specific 2-year period at risk. ${ }^{27}$

In multivariable analyses, we included the following covariates: family history of glaucoma defined as a self-report of glaucoma in a sibling, parent or child, African ancestry (yes/no), body mass index $(<22$, 22-23, 24-25, 26-27, 28-29, 30-34, 35+ kg/m²), alcohol consumption (indicators of quintiles), caffeine intake (indicators of quintiles), smoking (current, past, never), physical activity (quartiles of activity in MET h/week), hypertension (yes/no), diabetes (yes/no), and PMH use (current, past, never). Other reproductive covariates included were age at menarche $(<12,12,13,14+$ years $)$, OC use (never, $<2,2-4,5+$ years used), parity (nulliparous, 1-2 children, 3 children, $4+$ children), age at menopause ( $\leq 44,45-50,50-54,54+$ years) depending on the female reproductive factor of interest. Information on covariates were updated through the most recent biennial questionnaire before the 2-year risk period, whereas caffeine and alcohol consumption were assessed with repeated validated FFQs. ${ }^{28}$

In secondary analyses, we studied the relation between reproductive factors and POAG characterized by untreated IOP $>21 \mathrm{~mm} \mathrm{Hg}$ at or before the detection of visual field loss. If reproductive factors or OC use affect IOP, it is plausible that associations may be different in relation to the risk of POAG characterized with elevated or non-elevated IOP. In addition, because POAG is a strongly age-related disease, we stratified our population into those $<65$ and $\geq 65$ years of age to assess the relation between reproductive factors and POAG.

The Human Research Committees of the Partners Healthcare System approved this study. We certify that all applicable institutional and governmental regulations concerning the ethical use of human volunteers were followed during this research.

\section{Results}

From 1980 to 2006, we accrued nearly 1.3 million years of person-time and 813 POAG cases. We evaluated the various risk factors for POAG by the reproductive factors of interest. Women with later age at menarche were less likely to have hypertension and diabetes mellitus. Women with varying lengths of reproductive duration did not differ in the distribution of the POAG risk factors, except for current smoking status (Table 1). OC users tended to be $\mathrm{PMH}$ users, whereas nulliparous women 
Table 1 Age and age-adjusted characteristics by age at menarche, reproductive duration, ${ }^{\text {a }}$ oral contraceptive (OC) use, and parity in the Nurses' Health Study over the entire follow-up period

\begin{tabular}{|c|c|c|c|c|c|c|c|c|c|c|c|c|}
\hline & \multicolumn{4}{|c|}{ Age at menarche } & \multicolumn{4}{|c|}{ Reproductive duration } & \multicolumn{2}{|c|}{ OC use } & \multicolumn{2}{|c|}{ Parity } \\
\hline & $\begin{array}{l}<12 \\
\text { years }\end{array}$ & $\begin{array}{c}12 \\
\text { years }\end{array}$ & $\begin{array}{c}13 \\
\text { years }\end{array}$ & $\begin{array}{l}>13 \\
\text { years }\end{array}$ & $\begin{array}{l}<36 \\
\text { years }\end{array}$ & $\begin{array}{c}36-38 \\
\text { years }\end{array}$ & $\begin{array}{l}39-40 \\
\text { years }\end{array}$ & $\begin{array}{l}41+ \\
\text { years }\end{array}$ & $\begin{array}{l}\text { Never } \\
\text { user }\end{array}$ & $\begin{array}{l}\text { Ever } \\
\text { user }\end{array}$ & $\begin{array}{l}\text { Nulli- } \\
\text { parous }\end{array}$ & Parous \\
\hline African-American (\%) & 1.3 & 1.2 & 1.1 & 1.3 & 1.0 & 1.0 & 1.0 & 0.9 & 1.3 & 1.2 & 1.6 & 1.2 \\
\hline Family history of glaucoma (\%) & 13.1 & 13.2 & 12.4 & 12.3 & 12.2 & 12.0 & 12.2 & 12.5 & 12.3 & 13.3 & 12.8 & 12.8 \\
\hline Hypertension $(\%)$ & 39.2 & 35.8 & 33.7 & 31.9 & 37.5 & 37.6 & 38.6 & 41.2 & 33.3 & 37.0 & 34.7 & 35.1 \\
\hline Diabetes mellitus (\%) & 7.2 & 5.9 & 5.1 & 4.8 & 5.8 & 5.5 & 6.6 & 7.1 & 5.4 & 6.0 & 5.9 & 5.7 \\
\hline Current cigarette smoking (\%) & 15.5 & 14.9 & 15.1 & 16.1 & 19.2 & 15.4 & 12.9 & 9.0 & 15.9 & 14.7 & 17.2 & 15.2 \\
\hline Being in the top $25 \%$ of exercise $(\%)$ & 24.5 & 24.0 & 24.7 & 25.6 & 25.4 & 25.7 & 26.6 & 26.2 & 24.0 & 25.5 & 25.9 & 24.6 \\
\hline Ever use of oral contraceptives (\%) & 50.3 & 50.1 & 50.7 & 49.0 & 42.7 & 42.9 & 42.8 & 43.8 & 0 & 100 & 36.8 & 50.9 \\
\hline $\begin{array}{l}\text { Current use of postmenopausal } \\
\text { hormones }(\%)\end{array}$ & 30.0 & 29.7 & 30.0 & 29.2 & 27.2 & 28.4 & 27.8 & 27.8 & 24.3 & 35.7 & 32.9 & 29.6 \\
\hline Being parous $(\%)$ & 92.7 & 93.2 & 93.6 & 94.0 & 91.3 & 92.8 & 93.9 & 92.8 & 91.7 & 95.1 & 0 & 100 \\
\hline Mean alcohol intake $(\mathrm{g} / \text { day })^{\mathrm{b}}$ & 5.6 & 6.0 & 6.3 & 6.4 & 6.5 & 6.6 & 6.4 & 5.6 & 5.7 & 6.5 & 7.5 & 6.0 \\
\hline Mean caffeine intake $(\mathrm{mg} / \text { day })^{\mathrm{b}}$ & 324.4 & 322.6 & 321.0 & 319.5 & 331.9 & 318.0 & 308.8 & 292.5 & 329.9 & 314.9 & 318.3 & 322.1 \\
\hline Mean age at menarche (years) & 10.7 & 12.0 & 13.0 & 14.6 & 13.2 & 12.7 & 12.2 & 11.5 & 12.5 & 12.5 & 12.4 & 12.5 \\
\hline e at menopause (years) & 55.6 & 56.6 & 56.8 & 56.6 & 45.7 & 49.7 & 51.6 & 52.9 & 56.1 & 56.9 & 53.7 & 56.6 \\
\hline Mean number of eye exams reported & 5.9 & 5.9 & 5.9 & 5.6 & 5.9 & 6.0 & 6.1 & 6.2 & 5.3 & 6.3 & 5.6 & 5.9 \\
\hline
\end{tabular}

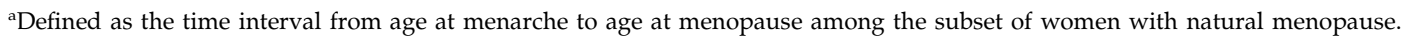

${ }^{\mathrm{b}}$ Cumulatively averaged intake.

tended to use OCs less frequently. We accounted for all these differences by adjusting for them in multivariable analyses.

We evaluated the association with age at menarche and the duration of reproductive years in relation to POAG. In multivariable analysis, there was no significant association between increasing age at menarche $(P$ for linear trend $=0.65$ ) or increasing reproductive duration $(P$ for linear trend $=0.30)$ and risk of POAG (Table 2$)$. The null associations were consistently observed in both the strata of younger ( $<65$ years old) and older $(\geq 65$ years old) participants for age at menarche. In secondary analysis, age at menarche $>13$ years was associated with an increased risk of normal tension POAG (MVRR $=1.47$; $95 \% \mathrm{CI}, 1.01,2.13)$ compared with having age at menarche $<12$ years ( $P$ for the difference in association with high-tension POAG vs normal-tension POAG $=0.02$ ). We did not observe associations of reproductive duration in relation to POAG overall or in relation to either of the subtypes of POAG defined by IOP level; associations also did not differ significantly by age.

Because OC use is common during the reproductive years, we were interested in the relation between OC use and POAG. We did not find significant associations between ever having used OCs and the risk of POAG or the subtypes of POAG (Table 3). However, we did find an adverse relation between longer duration of OC use and POAG. In a model that controlled for age at menarche, age at menopause, parity, and $\mathrm{PMH}$ use, there was a $25 \%$ increased risk of POAG associated with 5 or more years of OC use $(\mathrm{MVRR}=1.25 ; 95 \% \mathrm{CI}, 1.02,1.53 ; P$ for linear trend $=0.04)$. Although the formal test for interaction with age was not significant $(P$-interaction $=0.73)$, this positive association was more evident among those who were age $<65$ years: the MVRR for ever use was 1.32 (95\% CI, 1.04, 1.68) and the MVRR for $5+$ years of use was 1.47 (95\% CI, 1.09, 1.98; $P$ for linear trend $=0.01)$. OC use status or duration of use showed consistent weak adverse associations in relation to the risk of both high-tension and normal-tension POAG. In secondary analyses to evaluate whether detection bias may explain the association between long duration of OC use, which may be related to more eye exams, we repeated the multivariable analyses with additional adjustment for number of eye exams, and we observed almost identical results as the main results indicating that potential differences in eye exam frequency by duration was not explaining this association (MVRR with $5+$ years of OC use $=1.25 ; 95 \% \mathrm{CI}, 1.02,1.53 ; P$ for trend $=0.04$ ).

In addition, among past OC users, there was an inverse trend between time since stopping $\mathrm{OC}$ use and risk of POAG ( $P$ for linear trend $=0.02$; Table 3 ). Because there were no current OC users who developed POAG, the never users were considered the reference group in this analysis. Compared with never users, women who stopped using OCs $\geq 25$ years as of the latest 2-year period at risk did not have an increased risk of POAG (MVRR $=1.13 ; 95 \% \mathrm{CI}, 0.91,1.40)$, but women who discontinued OC use <10 years had a 39\% increased risk of POAG $(\mathrm{MVRR}=1.39 ; 95 \% \mathrm{CI}, 1.01,1.91)$. 
Table 2 RRs of POAG (95\% confidence intervals) by categories of age at menarche and reproductive duration

\begin{tabular}{|c|c|c|c|c|c|c|c|}
\hline & & \multicolumn{6}{|c|}{ Age at menarche (years) } \\
\hline & & $<12$ & 12 & 13 & $>13$ & P-trend ${ }^{\mathrm{b}}$ & P-trend ${ }^{c}$ \\
\hline \multirow[t]{2}{*}{ All POAG } & Cases & 172 & 205 & 241 & 190 & & \\
\hline & Person-years & 288270 & 344678 & 400956 & 254296 & & \\
\hline All & Age-adjusted RR & 1.0 (reference) & $0.97(0.79,1.19)$ & $0.97(0.79,1.17)$ & $1.11(0.90,1.37)$ & & \\
\hline All & MVRR $^{\mathrm{d}}$ & 1.0 (reference) & $0.92(0.75,1.13)$ & $0.94(0.77,1.15)$ & $1.06(0.86,1.31)$ & 0.54 & 0.65 \\
\hline$<65$ years & MVRR $^{\mathrm{d}}$ & 1.0 (reference) & $0.83(0.61,1.14)$ & $0.86(0.64,1.17)$ & $1.00(0.71,1.38)$ & 0.98 & 0.99 \\
\hline $65+$ years & MVRR $^{\mathrm{d}}$ & 1.0 (reference) & $1.02(0.76,1.37)$ & $1.02(0.77,1.36)$ & $1.19(0.88,1.60)$ & 0.27 & 0.37 \\
\hline High-tension POAG & $\operatorname{MVRR}^{\mathrm{d}}$ & 1.0 (reference) & $0.78(0.60,1.00)$ & $0.87(0.69,1.11)$ & $0.91(0.70,1.18)$ & 0.72 & 0.45 \\
\hline \multirow[t]{3}{*}{ Normal-tension POAG } & MVRR $^{\mathrm{d}}$ & 1.0 (reference) & $1.30(0.91,1.87)$ & $1.11(0.77,1.60)$ & $1.47(1.01,2.13)$ & 0.12 & 0.06 \\
\hline & \multicolumn{7}{|c|}{ Reproductive duration: time between age at menarche and age at menopause (years) ${ }^{\mathrm{e}}$} \\
\hline & & $<36$ & $36-38$ & $39-40$ & $41+$ & $P$-trend ${ }^{\mathrm{b}}$ & $P$-trend ${ }^{\mathrm{c}}$ \\
\hline \multirow[t]{2}{*}{ All POAG } & Cases & 115 & 146 & 106 & 100 & & \\
\hline & Person-years & 159521 & 189380 & 121454 & 117167 & & \\
\hline All & Age-adjusted RR & $0.94(0.72,1.24)$ & $0.93(0.73,1.20)$ & 1.0 (reference) & $0.95(0.72,1.25)$ & & \\
\hline All & MVRR $^{\mathrm{f}}$ & $0.93(0.71,1.22)$ & $0.94(0.73,1.21)$ & 1.0 (reference) & $0.96(0.73,1.27)$ & 0.72 & 0.30 \\
\hline$<65$ years & $M_{V R R}^{f}$ & $1.04(0.66,1.64)$ & $0.67(0.42,1.07)$ & 1.0 (reference) & $1.15(0.72,1.81)$ & 0.57 & 0.05 \\
\hline $65+$ years & MVRR $^{f}$ & $0.86(0.60,1.22)$ & $1.09(0.79,1.49)$ & 1.0 (reference) & $0.81(0.56,1.17)$ & 0.83 & 0.83 \\
\hline High-tension POAG & MVRR $^{f}$ & $0.84(0.59,1.19)$ & $0.88(0.64,1.21)$ & 1.0 (reference) & $1.02(0.73,1.44)$ & 0.21 & 0.17 \\
\hline Normal-tension POAG & $M_{V R R}^{f}$ & $1.08(0.70,1.67)$ & $1.03(0.68,1.55)$ & 1.0 (reference) & $0.85(0.53,1.38)$ & 0.34 & 0.99 \\
\hline
\end{tabular}

Abbreviations: MVRR, multivariable rate ratio; POAG, primary open-angle glaucoma; RRs, relative risks.

${ }^{a}$ Cases with missing values on age at menarche $(n=5)$ were excluded in the analysis.

${ }^{\mathrm{b}} P$-trend based on the median of each category.

${ }^{\mathrm{c}} P$-trend based on linear variable (years).

${ }^{\mathrm{d}} \mathrm{MVRR}=$ multivariable RR adjusting for the following: age (months), time-interval at risk, family history of glaucoma (yes, no, missing), African ancestry (yes, no), hypertension (yes, no), diabetes (yes, no), smoking status (current, past, never), cumulatively averaged alcohol intake (quintiles), cumulatively averaged caffeine intake (quintiles), body mass index ( $\left.<22,22-23,24-25,26-27,28-29,30-34,35+\mathrm{kg} / \mathrm{m}^{2}\right)$, physical activity (quartiles), postmenopausal hormone use (current, past, never), oral contraceptive use (never, $<2,2-4,5+$ years used), parity (nulliparous, $1-2$ children, 3 children, $4+$ children), and age at menopause (20-44, 45-50, 50-54, 54+ years)

e Only those with natural menopause and non-missing values for reproductive duration were included in the analysis $(n=467$ cases total).

${ }^{\mathrm{f}}$ Same covariates as the MVRR above in footnote $\mathrm{d}$, except the age at menopause variable was excluded.

Because pregnancy is associated with significant hormonal alterations, we explored the association between parity and POAG. We did not find significant associations between parity and risk of POAG in primary or secondary analysis (Table 4). Finally, accounting for breastfeeding did not materially alter the results (data not shown).

\section{Discussion}

Overall, in this large prospective study of 79440 women followed over $25+$ years, we found no significant associations between age at menarche, reproductive duration, parity, and POAG. We did find a modest but significantly adverse association between $5+$ years of OC use and POAG. We also found that a shorter time, as stopping OC among past users was also significantly associated with increased risk of POAG. Given the modest nature of our findings and that few studies have examined the association with OC use and POAG, these findings certainly require further scrutiny.

In the Blue Mountain Eye Study, later age at menarche was associated with an increased risk of open angle glaucoma. ${ }^{29}$ Although we did not find an association between age at menarche and POAG overall, in secondary analysis, age of menarche $>13$ years was associated with a $47 \%$ increased risk of the normal tension variant of POAG, defined as IOP $<22 \mathrm{~mm} \mathrm{Hg}$ at diagnosis. Previously we showed an inverse relation between body mass index (BMI) and the normal-tension variant of POAG in women, ${ }^{30}$ a finding that might also be explained by higher circulating estrogen levels in women with higher BMI. ${ }^{31-35}$ Previous work linking age at menopause with POAG, ${ }^{1,2}$ also supports the concept that circulating estrogen contributes to the glaucomatous process. We did not find an association between reproductive duration (age at menopause-age at menarche) and POAG. This finding is also consistent with results from other studies..$^{29,36}$ 
Table 3 RRs of POAG (95\% confidence intervals) by categories of oral contraceptive use

\begin{tabular}{|c|c|c|c|c|c|c|c|c|}
\hline \multirow[t]{3}{*}{ All POAG } & \multirow[t]{3}{*}{ Cases } & \multicolumn{7}{|c|}{ Oral contraceptive use $\mathrm{a}^{\mathrm{a}}$} \\
\hline & & \multicolumn{2}{|c|}{ Status } & \multicolumn{5}{|c|}{ Duration of use among ever users } \\
\hline & & $\begin{array}{c}\text { Never } \\
457\end{array}$ & $\begin{array}{c}\text { Ever } \\
333\end{array}$ & $\begin{array}{c}<2 \text { years } \\
123\end{array}$ & $\begin{array}{c}2-4 \text { years } \\
75\end{array}$ & $\begin{array}{c}5+\text { years } \\
135\end{array}$ & P-trend ${ }^{\mathrm{b}}$ & P-trend ${ }^{\mathrm{c}}$ \\
\hline & Person-years & 648238 & 619356 & 236743 & 168418 & 214196 & & \\
\hline All & Age-adjusted RR & 1.0 (reference) & $1.16(1.00,1.35)$ & $1.12(0.91,1.38)$ & $1.05(0.81,1.36)$ & $1.28(1.04,1.56)$ & & \\
\hline All & MVRR $^{d}$ & 1.0 (reference) & $1.14(0.98,1.34)$ & $1.10(0.89,1.36)$ & $1.04(0.81,1.35)$ & $1.25(1.02,1.53)$ & 0.05 & 0.04 \\
\hline$<65$ years & MVRR $^{d}$ & 1.0 (reference) & $1.32(1.04,1.68)$ & $1.26(0.93,1.71)$ & $1.20(0.83,1.72)$ & $1.47(1.09,1.98)$ & 0.02 & 0.01 \\
\hline $65+$ years & MVRR $^{\mathrm{d}}$ & 1.0 (reference) & $1.08(0.86,1.35)$ & $1.03(0.75,1.42)$ & $0.95(0.63,1.44)$ & $1.19(0.88,1.62)$ & 0.36 & 0.40 \\
\hline High-tension POAG & MVRR $^{\mathrm{d}}$ & 1.0 (reference) & $1.14(0.94,1.38)$ & $1.04(0.80,1.35)$ & $1.09(0.80,1.50)$ & $1.26(0.98,1.62)$ & 0.07 & 0.10 \\
\hline Normal-tension POAG & MVRR $^{d}$ & 1.0 (reference) & $1.16(0.89,1.51)$ & $1.22(0.86,1.72)$ & $0.95(0.61,1.49)$ & $1.23(0.87,1.74)$ & 0.38 & 0.22 \\
\hline \multirow[t]{2}{*}{ All POAG } & Cases & \multicolumn{7}{|c|}{ Time since quitting oral contraceptive use $e^{\mathrm{e}}$} \\
\hline & & $\begin{array}{c}\text { Never use } \\
457\end{array}$ & $\begin{array}{c}\geq 25 \text { years } \\
138\end{array}$ & $\begin{array}{c}20-24 \text { years } \\
72\end{array}$ & $\begin{array}{c}15-19 \text { years } \\
63\end{array}$ & $\begin{array}{c}<10 \text { years } \\
54\end{array}$ & P-trend $d^{b, d}$ & P-trend $d^{\mathrm{c}, \mathrm{f}}$ \\
\hline & Person-years & 648238 & 191322 & 119924 & 127810 & 162004 & & \\
\hline All & Age-adjusted RR & 1.0 (reference) & $1.12(0.91,1.39)$ & $1.08(0.83,1.40)$ & $1.23(0.93,1.63)$ & $1.46(1.06,2.01)$ & & \\
\hline All & MVRR $^{\mathrm{d}}$ & 1.0 (reference) & $1.13(0.91,1.40)$ & $1.06(0.82,1.38)$ & $1.20(0.91,1.59)$ & $1.39(1.01,1.91)$ & 0.18 & 0.02 \\
\hline$<65$ years & MVRR $^{\mathrm{d}}$ & 1.0 (reference) & $1.12(0.77,1.61)$ & $1.26(0.88,1.81)$ & $1.52(1.05,2.21)$ & $1.69(1.07,2.68)$ & 0.18 & 0.06 \\
\hline $65+$ years & MVRR $^{\mathrm{d}}$ & 1.0 (reference) & $1.18(0.90,1.54)$ & $0.96(0.63,1.46)$ & $1.15(0.67,1.96)$ & $0.37(0.05,2.69)$ & 0.77 & 0.26 \\
\hline High-tension POAG & MVRR $^{d}$ & 1.0 (reference) & $1.11(0.84,1.48)$ & $1.12(0.81,1.54)$ & $1.18(0.84,1.64)$ & $1.27(0.88,1.83)$ & 0.38 & 0.06 \\
\hline Normal-tension POAG & MVRR $^{\mathrm{d}}$ & 1.0 (reference) & $1.14(0.82,1.59)$ & $0.96(0.61,1.52)$ & $1.26(0.75,2.11)$ & $1.88(0.98,3.60)$ & 0.32 & 0.16 \\
\hline
\end{tabular}

Abbreviations: MVRR, multivariable rate ratio; POAG, primary open-angle glaucoma; RRs, relative risks.

${ }^{a}$ Cases with missing data on oral contraceptive use are not included in the analysis.

${ }^{\mathrm{b}} P$-trend based on the median of each category.

c $P$-trend based on linear variable (years).

${ }^{\mathrm{d}}$ MVRR = multivariable RR adjusting for the following: age (months), time-interval at risk, family history of glaucoma (yes, no, missing), African ancestry (yes, no), hypertension (yes, no), diabetes (yes, no), smoking status (current, past, never), cumulatively averaged alcohol intake (quintiles), cumulatively averaged caffeine intake (quintiles), body mass index $\left(<22,22-23,24-25,26-27,28-29,30-34,35+\mathrm{kg} / \mathrm{m}^{2}\right)$, physical activity (quartiles), postmenopausal hormone use (current, past, never), age at menopause (20-44, 45-50,50-54, $54+$ years), age at menarche $(<12,12,13,14+$ years), and parity (nulliparous, 1-2 children, 3 children, $4+$ children).

${ }^{\mathrm{e}}$ Cases with missing data on time since stopping oral contraceptive use are excluded from analysis.

${ }^{\mathrm{f}}$ Tests for trend conducted only among past users of oral contraceptives.

We found a null association between parity and POAG in a model that accounts for OC use, age at menarche and age at menopause. In contrast, the Blue Mountain Eye Study found an adverse association between parity and POAG. ${ }^{29}$ The null association in our study may be due to the control for OC use duration, as it was correlated with parity and was independently associated with POAG. Alternatively, it is possible that there are unknown biological factors that offset any protective effect of lower IOP that is encountered during pregnancy.

Although the associations between OC use and POAG reported here might be because of chance, it is reasonable to entertain possible biological hypotheses. OCs work by maintaining steady levels of estrogen and progesterone that inhibit follicle-stimulating hormone (FSH) and luteinizing hormone $(\mathrm{LH})$ production from the pituitary gland. The failure of FSH and LH production prevents ovulation and the secondary surges of estrogen and progesterone that would normally maintain robust uterine vascular and stromal support in anticipation of follicular implantation. ${ }^{37}$ OC use results in a thin endometrial lining depleted of a blood supply. Although OC use may actually result in decreased IOP, ${ }^{38}$ the resulting disruption of the physiological fluctuation of sex steroids may predispose to glaucomatous optic neuropathy just as OCs may predispose to ischemic stroke (although there is not complete consensus on this matter $)^{39-41}$ and retinal venous occlusive disease. ${ }^{42}$ Previous studies that evaluated the relation between ever use of OC agents (as opposed to duration of use) and POAG did not find any significant associations, a finding that is consistent with results we report here. ${ }^{29,42,43}$ To the best of our knowledge, no previous group has assessed the relation between duration of OC use or time since discontinuing $\mathrm{OC}$ use and the risk of POAG.

A significant strength of this study is that data on female reproductive factors was collected prospectively 
Table 4 RRs of POAG (95\% confidence intervals) by categories of parity

\begin{tabular}{|c|c|c|c|c|c|c|c|}
\hline \multicolumn{8}{|c|}{ Parity $^{\mathrm{a}}$} \\
\hline & & Nulliparous & 1-2 Children & 3 Children & $4+$ Children & P-trend ${ }^{\mathrm{b}}$ & P-trend ${ }^{c}$ \\
\hline \multirow[t]{2}{*}{ All POAG } & Cases & 37 & 254 & 235 & 280 & & \\
\hline & Person-years & 69918 & 448136 & 362274 & 400590 & & \\
\hline All & Age-adjusted RR & $0.84(0.59,1.18)$ & 1.0 (reference) & $1.08(0.90,1.29)$ & $1.00(0.84,1.19)$ & & \\
\hline All & MVRR $^{\mathrm{d}}$ & $0.85(0.60,1.21)$ & 1.0 (reference) & $1.08(0.90,1.29)$ & $1.00(0.84,1.19)$ & 0.50 & 0.83 \\
\hline$<65$ years & MVRR $^{\mathrm{d}}$ & $0.83(0.47,1.46)$ & 1.0 (reference) & $0.99(0.75,1.30)$ & $0.99(0.75,1.31)$ & 0.71 & 0.89 \\
\hline $65+$ years & $\mathrm{MVRR}^{\mathrm{d}}$ & $0.99(0.62,1.56)$ & 1.0 (reference) & $1.20(0.93,1.55)$ & $1.05(0.82,1.35)$ & 0.61 & 0.78 \\
\hline High-tension POAG & MVRR $^{d}$ & $0.67(0.42,1.07)$ & 1.0 (reference) & $1.00(0.80,1.26)$ & $1.03(0.83,1.28)$ & 0.16 & 0.95 \\
\hline Normal-tension POAG & MVRR $^{\mathrm{d}}$ & $1.23(0.72,2.07)$ & 1.0 (reference) & $1.22(0.90,1.65)$ & $0.93(0.68,1.26)$ & 0.43 & 0.66 \\
\hline
\end{tabular}

Abbreviations: MVRR, multivariable rate ratio; POAG, primary open-angle glaucoma; RRs, relative risks.

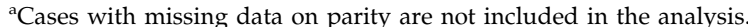

${ }^{\mathrm{b}} P$-trend based on the median of each category.

c $P$-trend based on linear variable (years).

${ }^{\mathrm{d}} \mathrm{MVRR}=$ multivariable RR adjusting for the following: age (months), time-interval at risk, family history of glaucoma (yes, no, missing), African ancestry (yes, no), hypertension (yes, no), diabetes (yes, no), smoking status (current, past, never), cumulatively averaged alcohol intake (quintiles), cumulatively averaged caffeine intake (quintiles), body mass index $\left(<22,22-23,24-25,26-27,28-29,30-34,35+\mathrm{kg} / \mathrm{m}^{2}\right)$, physical activity (quartiles), postmenopausal hormone use (current, past, never), age at menopause (20-44, 45-50,50-54, $54+$ years), age at menarche $(<12,12,13,14+$ years), and oral contraceptive use (never, $<2,2-4,5+$ years used).

on a large cohort (for cases, this means exposure was assessed previous to development of POAG) during the early 1980s when many of the participants in the cohort were in their reproductive years. This minimizes misclassification of exposures as well as recall bias. Many of the reproductive exposures including OC use have been previously validated. Finally, we were able to simultaneously control for attributes of reproductive aging in our various analyses. A significant weakness of this study is that we are not able to provide detailed assessment of the type of OCs used by participants (progesterone only vs combination estrogenprogesterone pill or dose of OC used). Furthermore, because our population was geographically dispersed, detailed eye exams on all participants were not feasible, and this could have lead to underdetection of POAG. Nonetheless, this is not likely to have biased the multivariable-adjusted relative rates, as systemic differential ascertainment of cases in the various categories of female reproductive factors is highly unlikely, and our case definition was highly specific. ${ }^{44}$

Although the associations between OC use and POAG and between later age at menarche and the normal-tension subtype of POAG are modest in nature, they can be added to the constellation of findings that support a role of circulating estrogen in the pathogenesis of POAG. We plan further studies of interactions between female reproductive attributes and common genetic variants in POAG with the hope of discovering more robust evidence for the role estrogen metabolism plays in the glaucomatous process.

\section{Summary}

What was known before

- Age at menarche and primary open-angle glaucoma (POAG): later age of menarche was associated with an increased risk of POAG. Oral contraceptive (OC) use and POAG: ever-using OCs was not associated with the risk of POAG.

What this study adds

- Age at menarche and POAG: later age of menarche was associated with an increased risk of the normal-tension variant POAG (IOP $<22 \mathrm{~mm} \mathrm{Hg}$ at diagnosis). OC use and POAG: the $\geq 5$ years of OC use was associated with a modestly increased risk of POAG. Also there was inverse association between time since stopping OC use and POAG among past OC users. These data add further support for a role of circulating estrogen in the pathogenesis of POAG. In this work, data on female reproductive health was collected before the diagnosis of POAG, reducing recall bias.

\section{Conflict of interest}

The authors declare no conflict of interest.

\section{Acknowledgements}

We thank the participants of the Nurses Health Study and Frank Spiezer and Susan Hankinson, the founding and current principal investigators of the Nurses Health Study. Finally, we also thank Rong Chen, Maureen Ireland and Ann Wohlhueter for their contributions to this study. Financial support for this work was 
provided by grants CA87969, CA55075, EY09611, HL35464, and EY015473 from the National Institutes of Health. A Physician Scientist Award from Research to Prevent Blindness in New York City also supports Dr Pasquale.

\section{References}

1 Hulsman CA, Westendorp IC, Ramrattan RS, Wolfs RC, Witteman JC, Vingerling JR et al. Is open-angle glaucoma associated with early menopause? The Rotterdam Study. Am J Epidemiol 2001; 154: 138-144.

2 Pasquale LR, Rosner BA, Hankinson SE, Kang JH. Attributes of female reproductive aging and their relation to primary open-angle glaucoma: a prospective study. J Glaucoma 2007; 16: 598-605.

3 Affinito P, Di Spiezio Sardo A, Di Carlo C, Sammartino A, Tommaselli GA, Bifulco G et al. Effects of hormone replacement therapy on ocular function in postmenopause. Menopause 2003; 10: 482-487.

4 Sorrentino C, Affinito P, Mattace Raso F, Loffredo M, Merlino P, Loffredo A et al. Effect of hormone replacement therapy on postmenopausal ocular function. Minerva Ginecol 1998; 50: 19-24.

5 Sator MO, Joura EA, Frigo P, Kurz C, Metka M, Hommer A et al. Hormone replacement therapy and intraocular pressure. Maturitas 1997; 28: 55-58.

6 Uncu G, Avci R, Uncu Y, Kaymaz C, Develioglu O. The effects of different hormone replacement therapy regimens on tear function, intraocular pressure and lens opacity. Gynecol Endocrinol 2006; 22: 501-505.

7 Altintas O, Caglar Y, Yuksel N, Demirci A, Karabas L. The effects of menopause and hormone replacement therapy on quality and quantity of tear, intraocular pressure and ocular blood flow. Ophthalmologica 2004; 218: 120-129.

8 Tint NL, Alexander P, Tint KM, Vasileiadis GT, Yeung AM, Azuara-Blanco A. Hormone therapy and intraocular pressure in nonglaucomatous eyes. Menopause 2010; 17: 157-160.

9 Kang JH, Wiggs JL, Rosner BA, Hankinson SE, Abdrabou W, Fan BJ et al. Endothelial nitric oxide synthase gene variants and primary open-angle glaucoma: interactions with gender and postmenopausal hormone use. Invest Ophthalmol Vis Sci 2010; 51: 971-979.

10 Munaut C, Lambert V, Noel A, Frankenne F, Deprez M, Foidart JM et al. Presence of oestrogen receptor type beta in human retina. Br J Ophthalmol 2001; 85(7): 877-882.

11 Morisette M, Al Sweidi S, Callier S, DiPaolo T. Estrogen and SERM neuroprotection in animal models of Parkinson's disease. Mol Cell Endocrinol 2008; 290: 60-69.

12 Carroll JC, Rosario ER, Villamagna A, Pike CJ. Continuous and cyclic progesterone differentially interact with estradiol in the regulation of Alzheimer-like pathology in female 3xtransenic-Alzheimer's disease mice. Endocrinology 2010; 151: 2713-2722.

13 Zhou X, Li F, Ge J, Sarkisian SR, Tomita H, Zaharia A et al Retinal ganglion cell protection by 17 -beta-estradiol in a mouse model of inherited glaucoma. Dev Neurobiol 2007; 67: 603-616.

14 Russo R, Cavaliere F, Watanabe C, Nucci C, Bagetta G, Corasaniti MT et al. 17 Beta-estradiol prevents retinal ganglion cell loss induced by acute rise of intraocular pressure in rat. Prog Brain Res 2008; 173: 583-590.
15 Phillips CI, Gore SM. Ocular hypotensive effect of late pregnancy with and without high blood pressure. Br J Ophthalmol 1985; 69: 117-119.

16 Qureshi IA. Intraocular pressure: association with menstral cycle, pregnancy and menopause in apparently healthy women. Chin J Physiol 1995; 38: 229-234.

17 Qureshi IA, Xi XR, Wu XD. Intraocular pressure trends in pregnancy and in the third trimester hypertensive patients. Acta Obstet Gynecol Scand 1996; 75: 816-819.

18 Green K, Phillips CI, Cheeks L, Siagle T. Aqueous humor flow rate and intraocular pressure during and after pregnancy. Ophthalmic Res 1998; 20: 353-357.

19 Weinreb RN, Lu A, Beeson C. Maternal corneal thickness during pregnancy. Am J Ophthalmol 1988; 105: 258-260.

20 Kang JH, Willett WC, Rosner BA, Hankinson SE, Pasquale LR. Prospective study of alcohol consumption and the risk of primary open-angle glaucoma. Ophthalmic Epidemiol 2007; 14: 141-147.

21 Kang JH, Willett WC, Rosner BA, Hankinson SE, Pasquale LR. Caffeine consumption and the risk of primary open-angle glaucoma: a prospective cohort study. Invest Ophthalmol Vis Sci 2008; 49: 1924-1931.

22 Hunter DJ, Manson JE, Colditz GA, Chasan-Taber L, Troy L, Stampfer MJ et al. Reproducibility of oral contraceptive histories and validity of hormone composition reported in a cohort of US women. Contraception 1997; 56: 373-378.

23 Colditz GA, Stampfer MJ, Willett WC, Stason WB, Rosner B, Hennekens $\mathrm{CH}$ et al. Reproducibility and validity of self-reported menopausal status in a prospective cohort study. Am J Epidemiol 1987; 126: 319-325.

24 Hankinson SE, Willett WC, Manson JE, Colditz GA, Hunter DJ, Spiegelman D et al. Plasma sex steroid hormone levels and risk of breast cancer in postmenopausal women. J Natl Cancer Inst 1998; 90: 1292-1299.

25 Missmer SA, Eliassen AH, Barbieri RL, Hankinson SE. Endogenous estrogen, androgen, and progesterone concentrations and breast cancer risk among postmenopausal women. J Natl Cancer Inst 2004; 96: 1856-1865.

26 Tworoger SS, Missmer SA, Barbieri RL, Willett WC, Colditz GA, Hankinson SE. Plasma sex hormone concentrations and subsequent risk of breast cancer among women using postmenopausal hormones. J Natl Cancer Inst 2005; 97: 595-602.

27 Cox DR, Oakes D. Analysis of Survival Data. Chapman and Hall: London, 1984.

28 Willett WC, Sampson L, Stampfer MJ, Rosner B, Bain C, Witschi $\mathrm{J}$ et al. Reproducibility and validity of a semiquantitative food frequency questionnaire. Am J Epidemiol 1985; 122: 51-65.

29 Lee AJ, Mitchell P, Rochtchina E, Healey PR. Female reproductive factors and open angle glaucoma: the Blue Mountains Eye Study. Br J Ophthalmol 2003; 87: 1324-1328.

30 Pasquale LR, Willett WC, Rosner BA, Kang JH. Anthropometric measures and their relation to incident primary open-angle glaucoma. Ophthalmology 2010; 117: 1521-1529.

31 Cauley JA, Gutai JP, Kuller LH, LeDonne D, Powell JG. The epidemiology of serum sex hormones in postmenopausal women. Am J Epidemiol 1989; 129: 1120-1131.

32 Kaye SA, Folsom AR, Soler JT, Prineas RJ, Potter JD. Associations of body mass and fat distribution with sex hormone concentrations in postmenopausal women. Int J Epidemiol 1991; 20: 151-156.

33 Hankinson SE, Willett WC, Manson JE, Hunter DJ, Colditz GA, Stampfer MJ et al. Alcohol, height, and 
adiposity in relation to estrogen and prolactin levels in postmenopausal women. J Natl Cancer Inst 1995; 87: 1297-1302.

34 Madigan MP, Troisi R, Potischman N, Dorgan JF, Brinton LA, Hoover RN. Serum hormone levels in relation to reproductive and lifestyle factors in postmenopausal women (United States). Cancer Causes Control 1998; 9: 199-207.

35 Verkasalo PK, Thomas HV, Appleby PN, Davey GK, Key TJ. Circulating levels of sex hormones and their relation to risk factors for breast cancer: a cross-sectional study in 1092 pre- and post-menopausal women (United Kingdom). Cancer Causes Control 2001; 12: 47-59.

36 Nirmalan PK, Katz J, Robin AL, Ramakrishnam R, Krishnadas R, Thulasiraj RD et al. Female reproductive factors and eye disease in a rural South Indian population: the Aravind Comprehensive Eye Survey. Invest Ophthalmol Vis Sci 2004; 45: 4273-4276.

37 Molina PE. Endocrine Physiology, 3rd edn. The McGraw-Hill Companies: New York, 2010.

38 Meyer EJ, Roberts CR, Leibowitz HM, McGowan B, Houle RE. Influence of norethynodrel with mestanol on intraocular pressure in glaucoma. II a controlled double-blind study. Arch Ophthalmol 1966; 75: 771-773.

39 Gillium LA, Mamidipudi SK, Johnston SC. Ischemic stroke risk with oral contraceptives. A meta-analysis. JAMA 2000; 284: 72-78.

40 Chan WS, Ray J, Wai EK, Ginsburg S, Hannah ME, Corey PN et al. Risk of stroke in women exposed to low-dose oral contraceptives:a critical evaluation of the evidence. Arch Intern Med 2004; 164: 741-747.

41 Baillargeon JP, McClish DK, Essah PA, Nestler JE. Association between the current use of low-dose oral contraceptives and cardiovascular arterial disease: a meta-analysis. J Clin Endocrinol Metab 2005; 90: 3863-3870.

42 Vessey MP, Hannaford P, Mant J, Painter R, Frith P, Chappel D. Oral contraceptives and eye disease: findings in two large cohort studies. Br J Ophthalmol 1998; 82: 538-542.

43 Doshi V, Ying-Lai M, Azen SP, Varma R, for The Los Angeles Latino Eye Study Group. Sociodemographic, family history, and lifestyle risk factors for open-angle glaucoma and ocular hypertension. Ophthalmology 2008; 115: 639-647.

44 Rothman K, Greenland S. Modern Epidemiology, 2nd edn. Lippincott-Raven Publishers: Philadelphia, 1998. 